12. Бобринский А.А. Гончарство Восточной Европы. Источники и методы изучения. М.: Наука, $1978.272 \mathrm{c}$

13. Бобринский А.А. Гончарная технология как объект историко-культурного изучения // Актуальные проблемы изучения древнего гончарства: кол. монография. Самара: СамГПУ, 1999. С. 5-109.

14. Андреев К.М., Выборнов А.А. Ранний неолит лесостепного Поволжья. Самара: ООО «ПортоПринт», 2017. 272 с.

15. Радиоуглеродная хронология эпохи неолита Восточной Европы VII-III тысячелетия до н.э.: кол. моногр. / сост. Г.И. Зайцева, О.В. Лозовская, А.А. Выборнов, А.Н. Мазуркевич. Смоленск: Изд-во Свиток, 2016. $456 \mathrm{c}$

16. Смольянинов Р.В. Ранний неолит Верхнего Дона (по данным керамических комплексов): автореф. дис. ... канд. ист. наук. СПб., 2009. 314 с.

17. Куличков А.А., Скоробогатов А.М., Юркина Е.С., Смольянинов Р.В. Разведочные исследования в Добровском районе Липецкой области в 2017 году (по материалам поселения Доброе 7) // Ар- хеология восточноевропейской лесостепи: сб. матлов междунар. науч.-практ. конф., посв. 80-летию со дня рожд. А.Г. Николаенко (г. Белгород, 14-16 декабря 2017 года) / отв. ред. В.А. Сарапулкин. Белгород: ИД «Белгород» НИУ «БелГУ», 2018. С. 56-78.

18. Смольянинов Р.В., Куличков А.А., Юркина Е.С. Стоянка среднедонской культуры Доброе 9 на Верхнем Дону // XXI Уральское археологическое совещание, посв. 85-летию со дня рожд. Г.И. Матвеевой и 70-летию со дня рожд. И.Б. Васильева: мат-лы всерос. науч. конф. с междунар. участием. Самара: Издво СГСПУ, 2018. С. 67-71.

19. Смольянинов Р.В., Куличков А.А., Клоков А.Ю. Керамика с поселения Доброе 4 (пункт 385) на Верхнем Дону // Тверской археологический сборник. Вып. 11. Тверь: Изд-во «Триада», 2018. С. 318-325.

Статья публикуется при поддержке гранта РФФИ проект 18-49-480004 р_а «Поселение Доброе 9 в системе ранненеолитических древностей лесостепного Подонья" и гранта Фонда президентских грантов.

\title{
MATERIALS OF THE EARLY NEOLITHIC OF THE YARLUKOVSKAYA PROTOKA SITE (POINT 222) ON THE UPPER DON
}

(C) 2019

Smolyaninov Roman Viktorovich, candidate of historical sciences, head of Archeology and Ethnology Office Lipetsk State Pedagogical P. Semenov-Tyan-Shansky University (Lipetsk, Russian Federation)

Kulichkov Aleksey Aleksandrovich, head of Local History Work Department Intersettlement Coordination and Methodological Center of Gryazinsky District of Lipetsk Region (Gryazi, Lipetsk Region, Russian Federation)

Yurkina Elizaveta Sergeevna, student of History, Law and Social Sciences Institute Lipetsk State Pedagogical P. Semenov-Tyan-Shansky University (Lipetsk, Russian Federation)

Abstract. This paper analyzes materials located in the floodplain of the Matyra River (left tributary of the Voronezh River) of the Yarlukovskaya Protoka (point 222) in the Gryazinsky District of the Lipetsk Region. It was investigated in 1963, 1964, 1967 and 1968 by Vsevolod Levenok. The materials of three early Neolithic cultures of VI Millennium BC were revealed here. The materials of the Yelshanskaya culture are represented by corollas and bottoms of 12 vessels. Almost all dishes, except one bottom and several walls, have no ornament, with the exception of one or two rows of conical pit. All ceramics are well smoothed. Ceramics were made from silty clay. The location of materials in the cultural layer confirms the earlier occurrence of the Yelshanskaya culture ceramics. The ceramics of the Karamyshevo culture is represented by fragments from three vessels. The dishes are predominantly decorated with small oval pricks composed in horizontal and vertical rows. Ceramics were made from silty clay. Ceramics of the Srednedonskaya culture are represented by corollas and rounded bottoms of 15 vessels. It is decorated with triangular prick or small comb prints. Ceramics were made from silty clay. At Yarlukovskaya Protoka site 304 stone artifacts were discovered, mainly of flint. This industry could be described as flake-blade technique. The monument is a mixed complex - stratigraphic and planigraphic readable observations of stone inventory location could not be done.

Keywords: Upper Don; forest-steppe; Early Neolithic; ceramics; temper; radiocarbon dating; flint; Srednedonskaya Neolithic culture; Karamyshevo Neolithic culture; Yelshanskaya Neolithic culture; prick; comb ornament; tool; flake; scraper; knife; polyfunctional tools; blade; core; typological analysis.

УДК 902

DOI 10.24411/2309-4370-2019-12219

Статья поступила в редакцию 24.01.2019

\section{СООТНОШЕНИЕ НЕОЛИТИЧЕСКИХ И ЭНЕОЛИТИЧЕСКИХ КОМПЛЕКСОВ ЛЕСОСТЕПНОГО ПОВОЛЖЬЯ ПО ДАННЫМ РАДИОУГЛЕРОДНОГО ДАТИРОВАНИЯ}

Сомов Анатолий Владимирович, магистрант кафедры отечественной истории и археологии, лаборант научно-исследовательской части

Шалапинин Антон Александрович, кандидат исторических наук, научный сотрудник научно-исследовательской части

Самарский государственный соџчильно-педагогический университет (2. Самара, Российская Федераџия)

Аннотация. В статье приведена база данных радиоуглеродного датирования, которая была получена по средневолжской археологической культуре развитого и позднего неолита, а также по энеолитическим материалам лесостепного Поволжья. Ключевым вопросом является хронологическое соотношение данных ком- 
плексов, которое рассматривается посредством построения графиков сумм калиброванных радиоуглеродных дат. Была проведена верификация ранее полученных определений с соотношением абсолютной хронологии сопредельных регионов. В результате исследования определений по С14 был выявлен диапазон сосуществования средневолжской неолитической культуры и энеолитических комплексов, который начинается с 5050 ВС при вероятности 68,2\% или 5250 ВС при вероятности 95,4\% и заканчивается 3900 ВС (68,2\%) или 4000 ВС (95,4\%). Результаты радиоуглеродного датирования подтверждают генетическую преемственность между неолитическими и энеолитическими комплексами лесостепного Поволжья. В свете данных по абсолютной хронологии предположение о преемственности между неолитом и энеолитом можно распространить и на бассейн р. Сок, где наблюдается смыкание хронологических диапазонов гребенчатых неолитических комплексов и энеолитических материалов чекалинского типа. Отметим, что хронологический интервал поздней неолитической керамики частично совпадает со временем существования токских материалов, а также с гундоровским типом и керамикой «с внутренним ребром».

Ключевые слова: абсолютная хронология; радиоуглеродный анализ; статистическая модель; лесостепное Поволжье; неолит; энеолит; керамическая традиция; керамика; средневолжская культура; самарская культура; хвалынская культура; лебяжинский тип; токский тип; гундоровский тип; керамика «с внутренним ребром»; чекалинский тип; турганикский тип.

В последнее время одним из приоритетных направлений в изучении позднего каменного века лесостепного Поволжья является определение хронологического положения неолитических и энеолитических комплексов. Работы ведутся по увеличению массива радиоуглеродных дат [1, с. 241-243; 2, с. 8396,3 , с. 267-269; 4, с. 55-56, 125, 131-132], их статистической обработке [5, с. 380-388], верификации полученных данных [6, с. 196-202]. В то же время все более актуальными становятся вопросы о сосуществовании неолитических и энеолитических комплексов и выделении особого нео-энеолитического периода на территории Среднего и Нижнего Поволжья $[7$, с. $54 ; 8$, с. $33 ; 9$, с. 102]. Решение данной проблемы без привлечения данных по С14 невозможно. Современное состояние корпуса радиоуглеродных дат, насчитывающего 130 определений, вызывает необходимость использования статистических методов при их анализе.

В настоящей работе будут проанализированы даты по неолитическим и энеолитическим материалам, с целью выявления периодов их совместного бытования. Для калибровки дат использовалась программа OxCal 3.10.

Радиоуглеродные определения (таблица № 1) введены в научный оборот [1, с. 241-243, табл. 1 ; 10 , с. $61-63 ; 11$, с. $121 ; 2$, с. $83-96$, табл. $1 ; 12$, с. $18-27$; 3 , с. $267-269 ; 13$, с. $221-232 ; 14$, с. 204 , табл. $1 ; 15$, p. 1594]. Даты по средневолжской неолитической культуре разделены на четыре группы: определения по C14, выполненные по керамике с накольчатым, гребенчатым, зубчатым орнаментом и по посуде с ногтевидными насечками. Радиоуглеродные даты для энеолитических комплексов сгруппированы по определениям по С14 для самарской и хвалынской культур, чекалинских, токских, гундоровских, турганикских материалов, а также типа Лебяжинка III и керамики «с внутренним ребром». Наиболее репрезентативной является выборка радиоуглеродных дат для накольчатых и зубчатых неолитических комплексов, самарской и хвалынской культур, материалов типа Лебяжинка III. Из 130 приведенных в таблице № 1 дат 107 получены по органике из керамики, 13 - по кости человека, 3 - по раковинам моллюсков, 4 - по костям животных, 2 - по нагару, 1 - по углю. Следует отметить совпадение большего числа датировок, выполненных по разным материалам. Так, дата $5950 \pm 120$ ВР (Spb-1759), полученная по фрагментам сосуда, орнаментированного оттисками короткого и длинного гребенчатого штампа, со стоянки Калмыковка I соответствует определению по кости лося $5989 \pm 70$ ВР (Spb-1876), найденной в скопле- нии данной керамики [16, с. 70]. Дата $5758 \pm 100$ ВР (Spb-2288) по кости медведя с поселения Лебяжинка III [15, p. 1594] совпадает с датировками по энеолитической керамике с указанного памятника $(5870 \pm 80$ BP Ki-15579, 5850 \pm 80 BP Ki-16289). Определения по С14, выполненные по кости КРС (5122 \pm 70 BP Spb-2290), происходящей из заполнения жилища на поселении Лебяжинка VI, связанного с керамикой «с внутренним ребром», частично коррелируются с датами, выполненными по данному типу посуды и нагару $(5299 \pm 120$ BP Spb-1736, $5325 \pm 110$ BP Spb-1736a) [14, c. 204]. Наиболее поздние даты по костям человека из хвалынских могильников совпадают с датировками по хвалынской керамике с поселений Лебяжинка IV и Гундровка. Даты по углю и раковинам речных моллюсков часто имеют более раннее значение по сравнению с определениями по C14, выполненными по керамике (Лебяжинка III), костям человека (Хвалынский I могильник).

При рассмотрении вопроса о хронологическом соотношении неолитических и энеолитических комплексов использовались графики сумм калиброванных радиоуглеродных дат, представленные в таблице № 2 .

\section{Средневолжская неолитическая культура}

По накольчатым материалам средневолжской неолитической культуры с Ивановской стоянки получены даты, которые укладываются в промежуток $6000-5700$ ВС $(68,2 \%)$ или 6100-5600 ВС $(95,4 \%)$. Стоит обратить внимание на то, что по результатам технико-технологического анализа накольчатая посуда Ивановской стоянки на $67 \%$ изготовлена из илов с добавлением раковины моллюсков $[17$, с. $30-$ 32]. Ввиду чего нельзя исключать, что полученные радиоуглеродные определения были подвержены резервуарному эффекту. Данная точка зрения нашла отражения в работах В.В. Ставицкого. Так, исследователь считает, что ивановские даты были удревнены в результате какого-то локального явления, а именно присутствия в образцах «геологического углерода» [18, с. 119]. Однако повторное датирование подтвердило раннюю позицию накольчатых комплексов. Так, в радиоуглеродной лаборатории РГПУ им. Герцена была получена дата по накольчатой посуде Ивановской стоянки (7100 \pm 100 BP Spb-583), которая совпала с уже имеющимися определениями по C14. Ввиду чего именно с этим временем, по нашему мнению, допустимо связывать проникновение орловского населения в лесостепное Поволжье и формирование в данном регионе накольчатой орнаментальной традиции. Были также получены радиоуглеродные определения накольчатой керамики, укладывающиеся в промежуток 5000-4500 ВС при вероят- 
Сомов А.В., Шалапинин А.А.

ности 68,2\% или 5400-4400 ВС при вероятности ления в то время, когда на Ивановской стоянке уже $95,4 \%$. Хронологический разрыв 5700-5000 ВС сложилась накольчатая орнаментальная традиция. $(68,2 \%)$ или 5600-5400 ВС $(95,4 \%)$ можно объяснить Нельзя также исключать и ограниченность источнитем, что основное население елшанской культуры ковой базы, которая связана с отсутствием материала испытало опосредованное влияние орловского насе- данного хронологического диапазона.

таблица 1 - Радиоуглеродные даты для неолитических и энеолитических комплексов лесостепного Поволжья

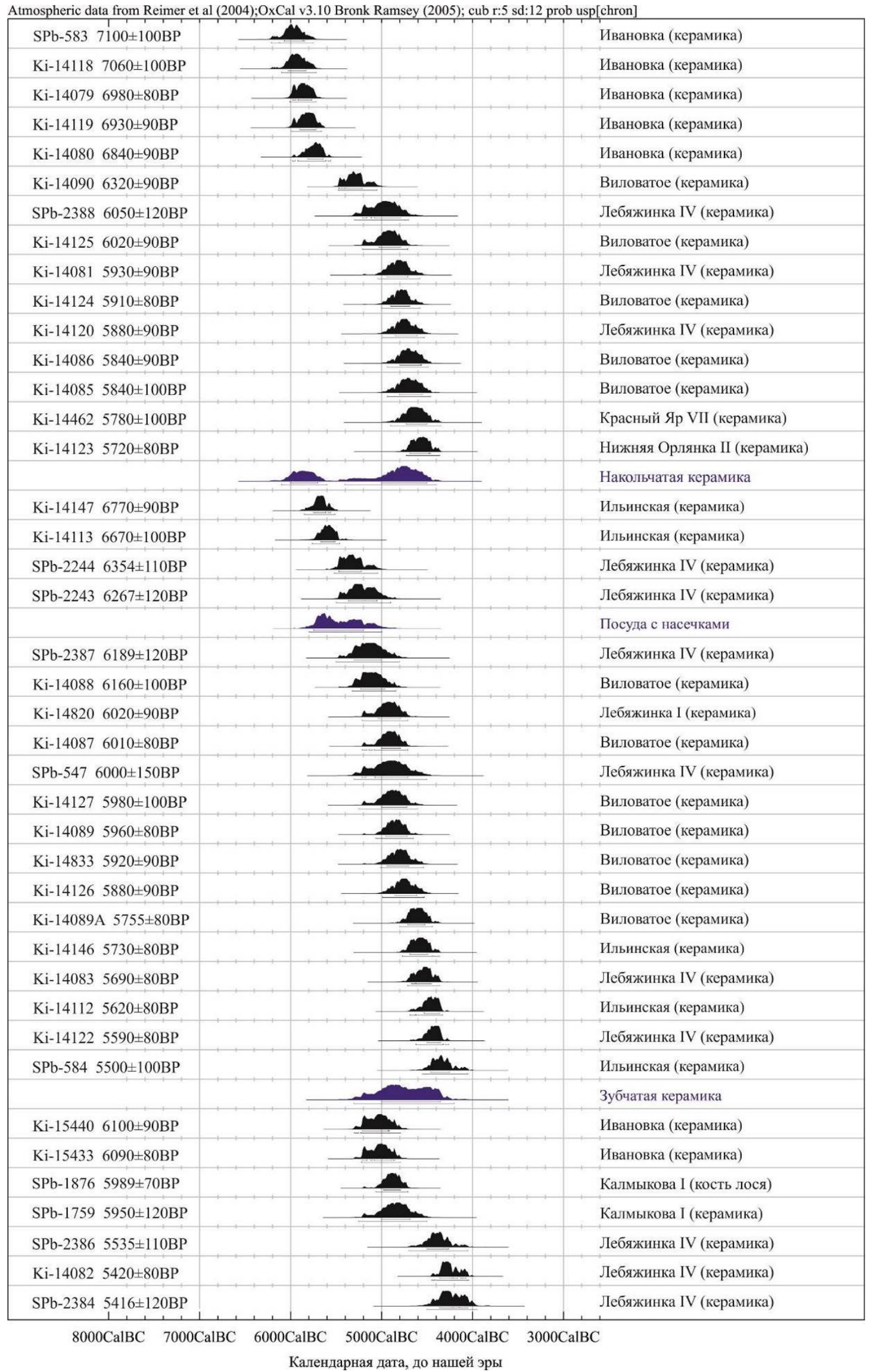


Сомов А.В., Шалапинин А.А.

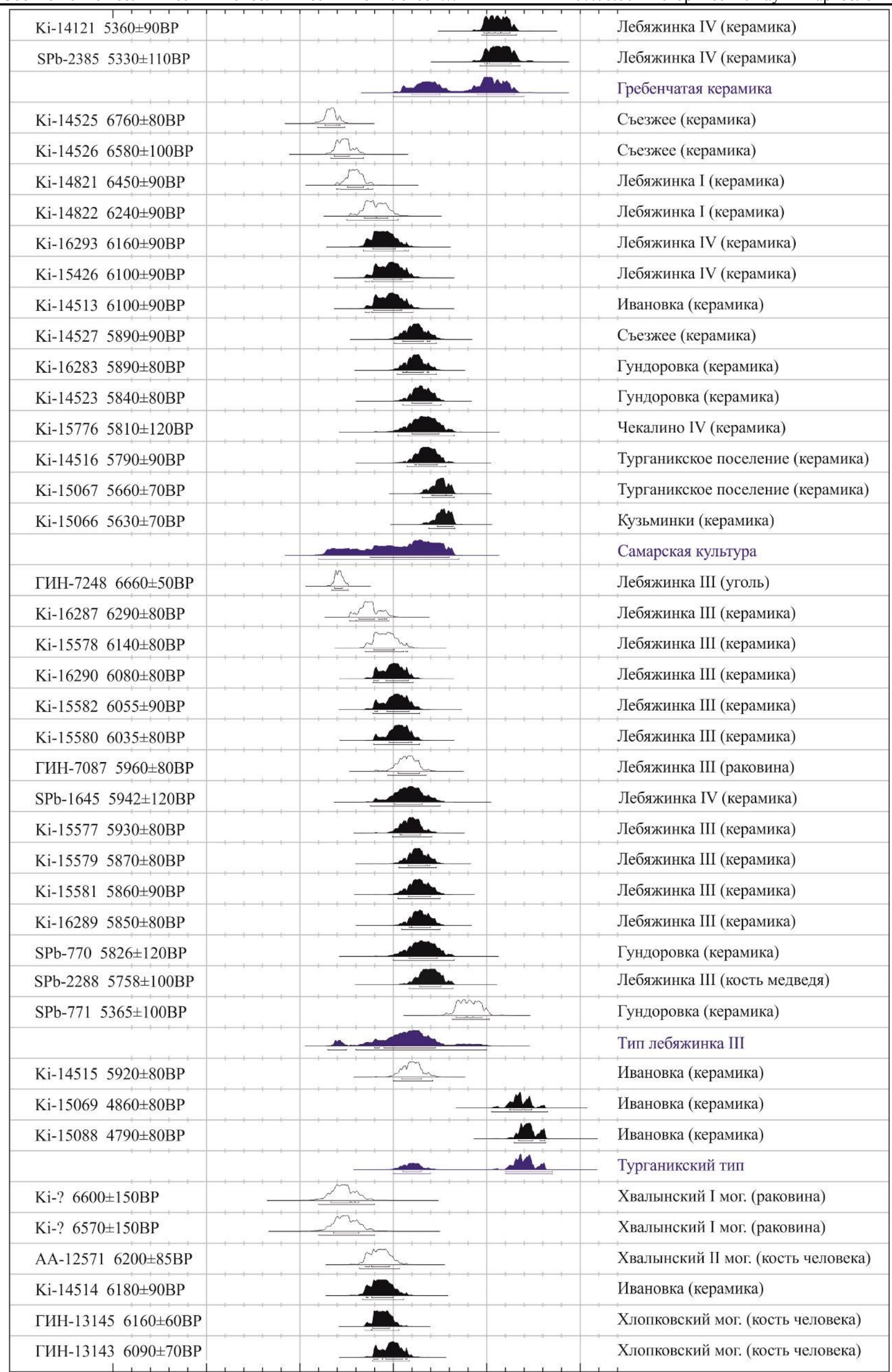

$8000 \mathrm{CalBC} \quad 7000 \mathrm{CalBC} \quad 6000 \mathrm{CalBC} \quad 5000 \mathrm{CalBC} \quad 4000 \mathrm{CalBC} \quad 3000 \mathrm{CalBC}$

Календарная дата, до нашей эры 
Сомов А.В., Шалапинин А.А.

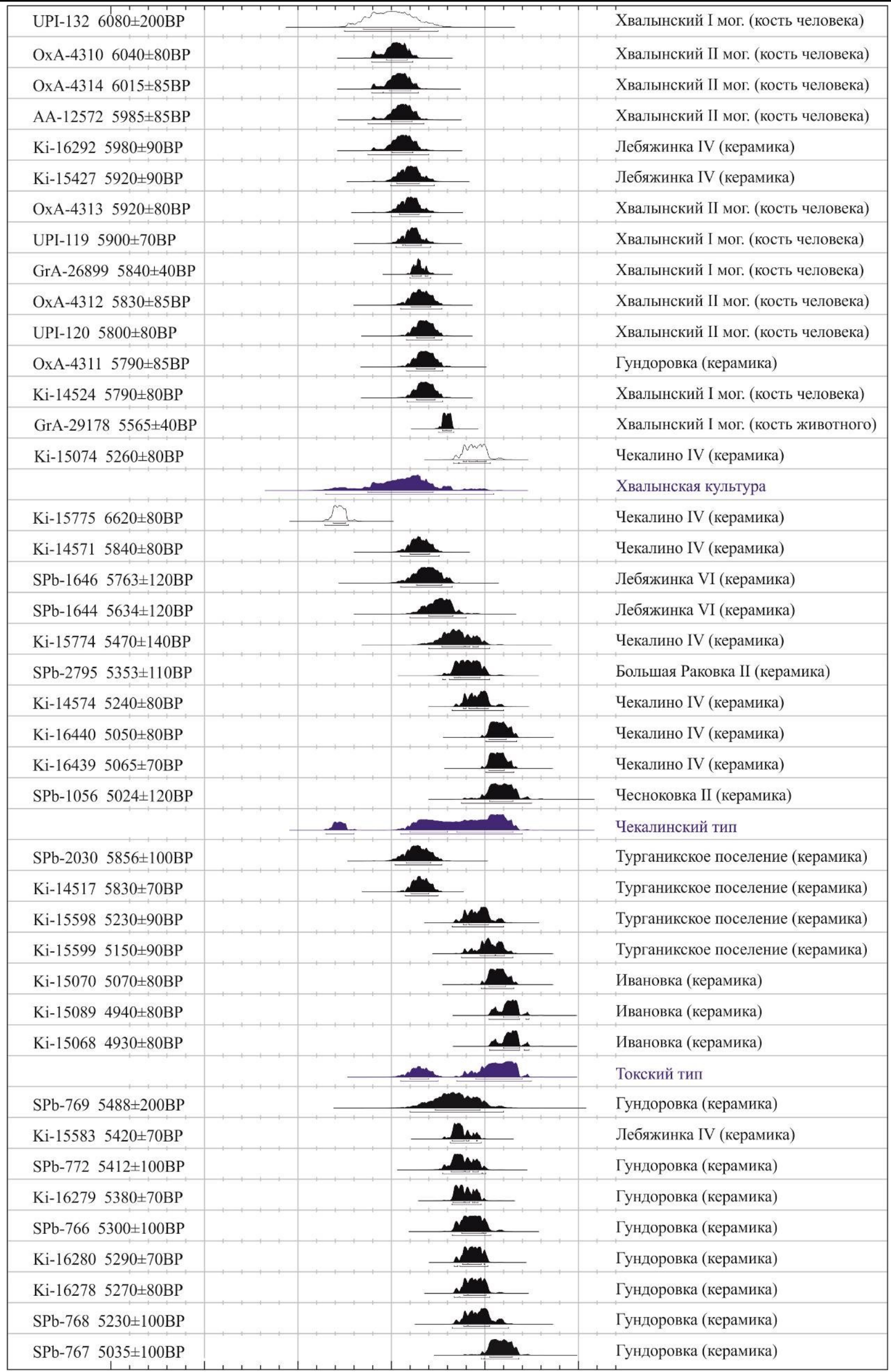

$8000 \mathrm{CalBC} \quad 7000 \mathrm{CalBC} \quad 6000 \mathrm{CalBC} \quad 5000 \mathrm{CalBC} \quad 4000 \mathrm{CalBC} \quad 3000 \mathrm{CalBC}$

Календарная дата, до нашей эры 
Сомов А.В., Шалапинин А.А.

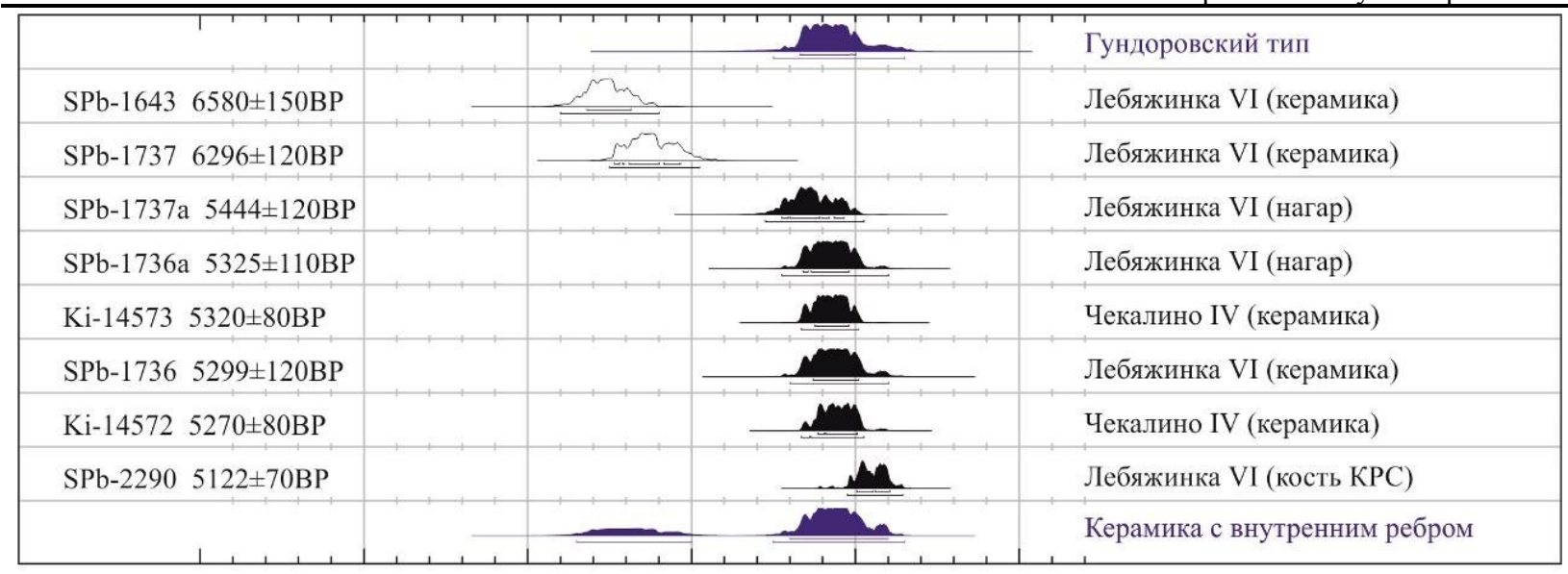

$8000 \mathrm{CalBC} \quad 7000 \mathrm{CalBC} \quad 6000 \mathrm{CalBC} \quad 5000 \mathrm{CalBC} \quad 4000 \mathrm{CalBC} 3000 \mathrm{CalBC}$

Календарная дата, до нашей эры

В промежутке между 5750-5200 ВС (68,2\%) или $5800-5000$ ВС $(95,4 \%)$ в лесостепном Поволжье распространяется посуда, украшенная ногтевидными насечками. Однако существует мнение, что данный тип посуды мог сформироваться значительно раньше $[10$, c. 60$]$. Подтверждением данной точки зрения может служить дата (по нагару) $6800 \pm 40$ BP (Poz65198), которая получена для аналогичной керамики нижнего слоя стоянки Алгай в степном Поволжье $[19$, с. 239]. Здесь стоит отметить, что указанный орнамент не характерен для степного региона, а в первую очередь соответствует лесостепной традиции Среднего Поволжья [20, с. 166]. Ввиду чего посуду с ногтевидными насечками на стоянке Алгай следует воспринимать заимствованной у населения лесостепного Поволжья, где данная орнаментальная традиция к этому времени должна была сформироваться.

Данному комплексу весьма близка керамика с зубчатым штампом, формирующаяся в данном регионе в пределах $5000-4350$ ВС $(68,2 \%)$ и 5300 4200 ВС (95,4\%). В связи с чем можно предположить автохтонное появление зубчатого штампа из ногтевидных насечек, но не исключается, что формирование данной орнаментальной традиции связано с контактами с представителями западных областей, где данная орнаментальная традиция складывается в промежутке между 5700-5450 ВС $(68,2 \%)$ или 5750 5350 ВС $(95,4 \%)$ [21, с. 104 , табл. 1: 8-10].

Распространение традиции орнаментации гребенчатом штампом приходится на 5100-4800 ВС $(68,2 \%)$ или 5300 ВС $(95,4 \%)$. Данный хроноинтервал вполне реален ввиду того, что гребенчатая посуда раннего этапа камской культуры, судя по радиоуглеродным определениям по керамике и нагару со стоянки Зиарат, на Нижней Каме формируется в интервале 5500-5300 ВС [16, с. 75]. Гребенчатая посуда в лесостепном Поволжье продолжает бытовать после исчезновения зубчато-накольчатой вплоть до 4000 ВС (68,2\%) или 3900 ВС (95,4\%). Данные определения также хорошо согласуются с полученными датировками позднего этапа камской культуры [22, c. $130 ; 23$, c. $140-141]$.

\section{Самарская культура}

Время существования самарской культуры определяется широким промежутком: между $5250 \mathrm{BC}$ и 4400 ВС при вероятности $68,2 \%$ или 5800 ВС и 4300
ВС при вероятности 95,4\%. Столь широкий диапазон вызывает сомнения в связи с недостаточностью и противоречивостью радиоуглеродных определений по Съезженскому могильнику: $6760 \pm 80$ BP (Ki14525), $6580 \pm 100 \mathrm{BP}(\mathrm{Ki}-14526), 5890 \pm 90 \mathrm{BP}(\mathrm{Ki}-$ 14527).

Также вызывает сомнения дата, полученная по керамике со стоянки Лебяжинка I $6450 \pm 90$ ВP (Ki14821), имеющая более раннее значение относительно основного массива радиоуглеродных определений по самарским материалам. В свете современного состояния базы определений по С14 время существования самарской энеолитической культуры приходится на 5050-4950 и 4900-4400 ВС $(68,2 \%)$ или $5250-4350$ ВC $(95,4 \%)$.

Время существования материалов типа Лебяжинка III определяется в интервале 5050-4950 и 4900-4400 ВС (68,2\%) или 5250-4350 ВС $(95,4 \%)$. Даты $6660 \pm 50$ ВР (ГИН-7248), $6290 \pm 80$ ВР (Ki16287), $6140 \pm 80$ ВР (Кi-15578), по нашему мнению, представляются более древними. Здесь стоит отметить, что столь раннее определение по углю $(6660 \pm 50$ ВР), которое является наиболее валидным датирующимся веществом, объясняется исследователями загрязнением образца во время отбора [4, c. 56]. Определения, полученные по раковине моллюсков, также вызывают сомнения ввиду самого датирующего материала, который подвержен резервуарному эффекту. Кроме этого, дата по керамике Гундоровского поселения (5365 $\pm 100 \mathrm{BP})$ находится на более поздних позициях относительно основного массива дат, ввиду чего не будет учитываться при построении абсолютной хронологии.

\section{Хвальнская культура}

Материалы хвалынской энеолитической культуры, так же как и материалы самарской культуры, датируются широким диапазоном 5250-4550 ВС или 5700-3900. Наиболее древние радиоуглеродные определения $(6570 \pm 150 \mathrm{BP} \mathrm{Ki}-?$ и $6600 \pm 150 \mathrm{BP} \mathrm{Ki}-$ ?), полученные по раковинам моллюсков, следует считать не валидными ввиду наличия резервуарного эффекта. Верхняя граница тоже нуждается в сокращении, что объясняется малой выборкой и разбросом определений С14. Ввиду чего дату $5260 \pm 80$ ВР (Ki-15074) на данный момент не учитывали. Таким образом, интервал 5030-4590 ВС $(68,2 \%)$ или 5250- 
Сомов А.В., Шалапинин А.А.

4350 ВС (95,4\%) следует считать наиболее валидным при определении времени бытования хвалынского населения в лесостепном Поволжье. Однако данный хронологический интервал имеет более ранние значения (на 100-250 лет) относительно диапазона хвалынских материалов Северного Прикаспия и степного Поволжья, который определяется по наиболее валидным определениям в интервал 4850-4450 ВС $(68,2 \%)$ или 5000-4250 ВС $(95,4 \%)$ [24, с. 189]. Это можно объяснить тем, что основным датирующим материалам хвалынских комплексов лесостепного Поволжья являлись кости человека, которые могут быть удревнены из-за употребления водных продуктов питания.

Время существования токского типа в лесостепном Поволжье приходится на промежуток 4800-4600 и $4100-3600 \mathrm{BC}(68,2 \%)$ или $4900-4500$ и 4300 3500 ВС (95,4\%). Первый хроноинтервал, несмотря на то, что подкреплен только двумя радиоуглеродными датами, вполне отвечает тому содержанию, которое было вложено в понятие «токский тип» Н.Л. Моргуновой. Данные материалы она связывала с безворотничковой керамикой, синхронной второму (ивановскому) этапу самарской культуры [25, с. 64]. Второй хронологический интервал позволяет отнести керамические комплексы токского типа к позднеэнеолитическому времени. В данном случае разделение времени существования указанного типа керамики на два промежутка связано с ограниченностью выборки радиоуглеродных дат.

Радиоуглеродные даты, полученные по чекалинским материалам, указывают на время их существования в диапазоне от 4800 до 3600 ВС при допуске 95,4\% или 4800-4500 ВС и 4300-3700 ВС при допуске $68,2 \%$. При этом из десяти имеющихся радиоуглеродных дат только одна $6620 \pm 80$ (Ki-15775) явно удревнена.

Определения по С14 для гундоровского комплекса указывают промежуток 5300-3900 ВС при вероятности 95,4\% или 4349-4030 ВСи 4020-4000 ВС при вероятности $68,2 \%$.

Керамика «с внутренним ребром» имеет компактную абсолютную хронологию 4320-4000 ВС $(68,2 \%)$ или $4450-3950$ BC (95,4\%). Две даты $6580 \pm 150 \mathrm{BP}(\mathrm{SPb}-1643)$ и $6296 \pm 120 \mathrm{BP}(\mathrm{SPb}-1737)$ не могут быть признаны валидными ввиду того, что они противоречат существующим представлениям о периодизации энеолита лесостепного Поволжья.

Для керамики турганикского типа наиболее вероятным является диапазон 3710-3510 ВС (68,2\%) или 3790-3490 и 3470-3370 ВС $(95,4 \%)$.

При сравнении хронологических интервалов средневолжской и самарской культур наблюдается следующее: данные культуры синхронны как на съезжинском, так и на ивановском этапах развития самарских материалов, и накольчатые комплексы обладают хронологическим приоритетом относительно воротничковой керамики. Аналогичная картина совпадения хронологических диапазонов прослеживается при сопоставлении радиоуглеродных датировок средневолжской культуры и материалов хвалынской культуры и керамики типа Лебяжинка III. Кроме этого, наблюдается частичное совпадение хронологических интервалов гребенчатых керамичеСамарский научный вестник. 2019. Т. 8, № 2 (27) ских комплексов средневолжской культуры с определениями по материалам токского и чекалинского типов, а также гундоровских материалов и керамики «с внутренним ребром».

Сравнение диапазонов радиоуглеродных дат средневолжской неолитической культуры и энеолитических комплексов лесостепной зоны Среднего Поволжья выявило период их сосуществования, который начинается со времени появления материалов эпохи раннего металла на данной территории 5050 ВС $(68,2 \%)$ или 5250 ВС $(95,4 \%)$ и заканчивается $3900 \mathrm{BC}(68,2 \%)$ или 4000 ВС $(95,4 \%)$. Средневолжские неолитические комплексы находятся на одних хронологических позициях с самарской и хвалынской культурами, воротничковой керамикой типа Лебяжинка III. Наблюдается частичное совпадение интервалов радиоуглеродных дат неолитической керамики с наиболее ранними определениями токского и чекалинского типов, а также гундоровских материалов и керамики «с внутренним ребром». Не противоречат полученным результатам данные о планиграфическом и стратиграфическом контексте залегания неолитических и энеолитических комплексов на памятниках лесостепной зоны Среднего Поволжья. Так, на Съезжинском могильнике гребенчатая и воротничковая керамика располагалась на одних площадках [26, с. 148]. На стоянке Лебяжинка I хвалынская керамика на отдельных участках залегала ниже гребенчатой посуды [27, с. 148]. На Большераковской II стоянке керамика чекалинского типа находилась ниже уровня расположения комплекса так называемой «волосовской» посуды [28, с. 118], рассматриваемой одним из автором настоящей работы в рамках гундоровских материалов. На поселении Лебяжинка VI чекалинские материалы залегали либо на одном уровне с керамикой с «внутренним ребром», либо ниже его [29, с. 83].

Специалистами неоднократно ставился вопрос о генетической преемственности между неолитическим и энеолитическим населением лесостепного Поволжья и, в частности, между гребенчатой неолитической посудой и материалами токского типа. Так, Н.Л. Моргунова связывала происхождение комплексов указанного типа с безворотничковой керамикой Съезжинского могильника [25, с. 64]. И.Б. Васильев при рассмотрении возможной основы для формирования токского типа не исключал в качестве таковой неолитическую гребенчатую керамику [30, с. 67]. Результаты радиоуглеродного датирования подтверждают указанное предположение. В свете данных по абсолютной хронологии предположение о преемственности между неолитом и энеолитом можно распространить и на бассейн р. Сок, где наблюдается смыкание хронологических диапазонов гребенчатых неолитических комплексов и чекалинских материалов.

Таким образом, в свете радиоуглеродного датирования наблюдается сосуществование комплексов средневолжской неолитической культуры и материалов самарской и хвалынской культур, воротничковой керамикой типа Лебяжинка III. Хронологический интервал поздней неолитической керамики частично совпадает со временем существования токских и чекалинских материалов, а также с гундоровским типом и керамикой «с внутренним ребром». 
Сомов А.В., Шалапинин А.А.

Таблица 2 - Графики сумм калиброванных радиоуглеродных дат для неолита и энеолита лесостепного Поволжья

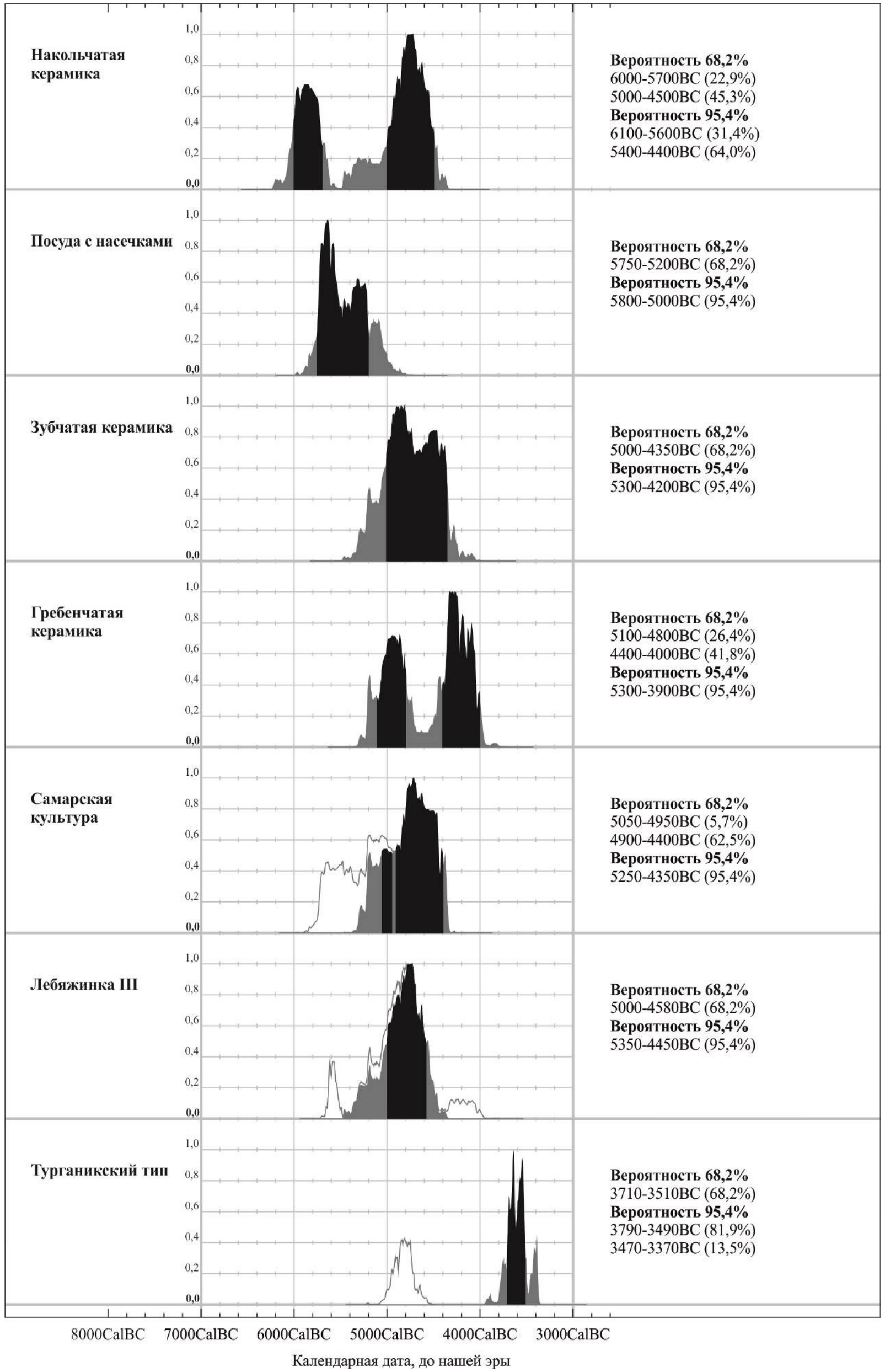




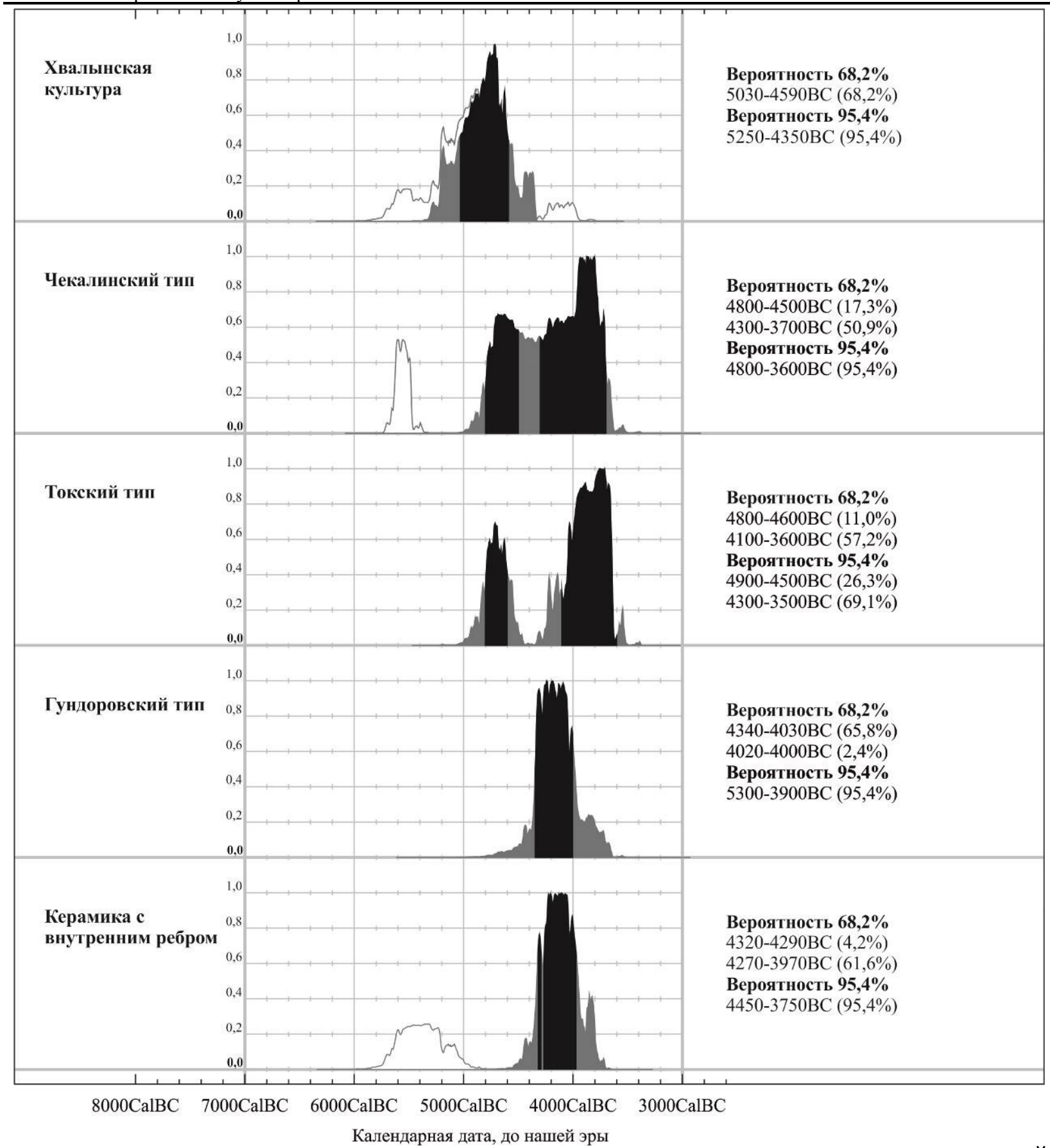

\section{Список литературы:}

1. Выборнов А.А. Неолит Волго-Камья. Самара: СГПУ, 2008. $490 \mathrm{c}$.

2. Выборнов А.А., Андреев К.М., Кулькова М.А., Нестеров Е.М. Радиоуглеродные данные к хронологии неолита лесостепного Поволжья // Радиоуглеродная хронология эпохи неолита Восточной Европы VII-III тысячелетия до н.э. Смоленск: Свиток, 2016. C. $74-96$.

3. Королев А.И., Шалапинин А.А. К вопросу о хронологии и периодизации энеолита степного и лесостепного Поволжья // Известия Самарского научного центра РАН. 2014. Т. 16, № 3. С. 266-275.

4. Моргунова Н.Л. Энеолит Волжско-Уральского междуречья. Оренбург: ОГПУ, 2011. 220 с.

5. Шалапинин А.А. К вопросу о хронологическом соотношении неолитических и энеолитических комплексов лесостепного Поволжья // Известия Самарского научного центра РАН. 2017. Т. 19, № 3 (2). C. $380-388$.
6. Шишлина Н.И., Турецкий М.А., ван дер Плихт Й. Радиоуглеродное датирование образцов из могильника Лебяжинка V эпохи энеолита: верификация и интерпретация // Известия Самарского научного центра РАН. 2017. Т. 19, № 3. С. 196-202.

7. Лебедева Н.В. Соотношение поздненеолитических и энеолитических комплексов в лесостепном Поволжье // Неолитические культуры Восточной Европы: хронология, палеоэкология, традиции. СПб.: ИИМК РАН, 2015. С. 54-55.

8. Ставицкий В.В. К вопросу о выделении неоэнеолитической эпохи в Поволжье // Проблемы периодизации и хронологии в археологии эпохи раннего металла Восточной Европы. СПб.: Скифия-принт, 2013. С. 31-33.

9. Юдин А.И. Поселение Кумыска и энеолит степного Поволжья. Саратов: Научная книга, 2012. 212 с.

10. Выборнов А.А., Ковалюх Н.Н., Скрипкин В.В. К радиокарбоновой хронологии неолита Среднего Поволжья: восточный регион // Российская археология. 2009. № 3. С. 58-65. 
11. Черных Е.Н., Орловская Л.Б. Радиоуглеродная хронология Хвалынских некрополей // Хвалынские энеолитические могильники и хвалынская энеолитическая культура. Исследования материалов. Самара: СРОО ИЭКА «Поволжье», 2010. С. 121-129.

12. Моргунова Н.Л., Выборнов А.А., Ковалюх Н.Н., Скрипкин В.В. Хронологическое соотношение энеолитических культур Волго-Уральского региона в свете радиоуглеродного датирования // Российская археология. 2010. № 4. С. 18-27.

13. Моргунова Н.Л., Васильева И.Н., Кулькова М.А., Рослякова Н.В., Салугина Н.П., Турецкий М.А., Файзуллин А.А., Хохлова О.С. Турганикское поселение в Оренбургской области. Оренбург: ОГАУ, 2017. 300 с.

14. Королев А.И., Кулькова М.А., Шалапинин А.А., Нестерова Л.А. Результаты радиоуглеродного датирования энеолитических материалов поселения Лебяжинка VI // Известия Самарского научного центра PAH. 2017. T. 19, № 3. C. 203-206.

15. Korolev A., Kulkova M., Platonov N., Shalapinin A., Yanish E. Archaeological materials of eneolithic settlements in forest-steppe zone of the Volga region: a source for diet and chronology // Radiocarbon. 2018. Vol. 60, № 5. P. 1587-1596.

16. Выборнов А.А., Андреев К.М., Кулькова М.А., Филипсен Б. Радиоуглеродная хронология неолита Волго-Камья // Уральский исторический вестник. 2018. № 3 (60). С. 66-77.

17. Васильева И.Н. О гончарной технологии населения Волго-Уралья в эпоху неолита (по материалам Ивановской стоянки) // Археологические памятники Оренбуржья. Оренбург: ОГПУ, 2007. С. 23-38.

18. Ставицкий В.В. К вопросу о взаимодействии неолитического населения степной и лесостепной зоны в Поволжье // Самарский научный вестник. 2014. № 4 (9). C. 117-121.

19. Выборнов А.А., Юдин А.И., Васильева И.Н., Косинцев П.А., Кулькова М.А., Гослар Т., Дога Н.С. Новые данные по неолиту - энеолиту Нижнего Поволжья // Известия Самарского научного центра РАН. 2015. T. 17, № 3. C. 235-241.

20. Выборнов А.А., Королев А.И., Мамонов А.Е. Комплекс каменного века поселения Лебяжинка V // Исторические исследования. Вып. 4. Самара: СГПУ, 2002. C. $163-176$.

21. Выборнов А.А., Ставицкий В.В., Кулькова М.А., Ойнонен М., Посснерт Г. Радиоуглеродные данные к хронологии неолита Примокшанья // Радиоуглерод- ная хронология эпохи неолита Восточной Европы VII-III тысячелетия до н.э. Смоленск: Свиток, 2016. C. 97-106.

22. Выборнов А.А., Морозов В.В. Радиоуглеродные данные по неолиту Нижнего Прикамья // Радиоуглеродная хронология эпохи неолита Восточной Европы VII-III тыс. до н.э. Смоленск: Свиток, 2016. C. 129-139.

23. Лычагина Е.Л. Радиоуглеродная хронология неолита Верхнего и Среднего Прикамья и КамскоВятского междуречья // Радиоуглеродная хронология эпохи неолита Восточной Европы VII-III тыс. до н.э. Смоленск: Свиток, 2016. С. 140-158.

24. Выборнов А.А., Юдин А.И., Васильева И.Н., Косинцев П.А., Кулькова М.А., Дога Н.С., Попов А.С. Новые материалы исследований на поселении Орошаемое в Нижнем Поволжье // Известия Самарского научного центра РАН. 2017. Т. 19, № 3. С. 185-190.

25. Моргунова Н.Л. Неолит и энеолит юга лесостепи волго-уральского междуречья. Оренбург: Южный Урал, 1995. 222 с.

26. Васильев И.Б., Матвеева Г.И. Могильник у с. Съезжее на р. Самаре // Советская археология. 1979. № 4. C. 147-166.

27. Барынкин П.П., Козин Е.В. Стоянка Лебяжинка I и некоторые проблемы соотношения нео-энеолитических культур в степном и южном лесостепном Заволжье // Древние культуры лесостепного Поволжья (к проблеме взаимодействия индоевропейских и финноугорских культур): сб. науч. тр. Самара: СамГПУ, 1994. С. 136-164.

28. Барынкин П.П., Козин Е.В. Некоторые результаты исследований II Больше-Раковской стоянки // Древности Восточно-Европейской лесостепи. Самара: СГПИ, 1991. С. 94-119.

29. Королев А.И., Шалапинин А.А. Поселение Лебяжинка VI - памятник эпохи энеолита в лесостепном Поволжье // Поволжская археология. 2017. № 1. C. $71-91$.

30. Васильев И.Б. Поздний энеолит юга лесостепного Поволжья // Энеолит лесного Урала и Поволжья. Ижевск: Удмурт. ин-т истории, языка и литературы УрО РАН, 1990. С. 52-69.

Работа подготовлена в рамках выполнения Государственного задания Минобрнауки РФ, проекm № 33.1907.2017/ПЧ.

\section{THE RATIO OF THE NEOLITHIC AND ENEOLITHIC COMPLEXES OF THE FOREST-STEPPE VOLGA REGION ACCORDING TO RADIOCARBON DATING} (C) 2019

Somov Anatoly Vladimirovich, master student of Domestic History and Archeology Department, laboratory assistant of Scientific Department

Shalapinin Anton Aleksandrovich, candidate of historical sciences, researcher of Scientific Department Samara State University of Social Sciences and Education (Samara, Russian Federation)

Abstract. The following paper provides a database of radiocarbon dating, which was obtained from the Srednevolzhskaya archaeological culture of the developed and late Neolithic, as well as on the Eneolithic materials of the forest-steppe Volga region. The key issue is the chronological ratio of the melon complexes, which is considered through the construction of graphs of the sums of calibrated radiocarbon dates. Verification of previously obtained definitions was carried out with the ratio of the absolute chronology of adjacent regions. As a result of definitions study for C14, the range of the Srednevolzhskaya Neolithic culture and the Eneolithic complexes coexistence was revealed, which begins with $5050 \mathrm{BC}$ with a probability of $68,2 \%$ or $5250 \mathrm{BC}$ with a probability of $95,4 \%$ and ends with $3900 \mathrm{BC}(68,2 \%)$ or $4000 \mathrm{BC}(95,4 \%)$. The results of radiocarbon dating confirm the genetic continuity between the Neolithic and Eneolithic complexes of the forest-steppe Volga region. In the light of data on the absolute 
chronology, the assumption of continuity between the Neolithic and Eneolithic can be extended to the basin of the Sok River, where there is a closure of a chronological range of comb Neolithic complexes and aneolithic materials of the Chekalinskiy type. The chronological interval of the late Neolithic ceramics partially coincides with the time of the existence of Tokskiy materials, as well as with the Gundorovskiy type and «with an internal edge» ceramics.

Keywords: absolute chronology; radiocarbon analysis; statistical model; forest-steppe Volga region; neolithic; eneolithic; ceramic tradition; pottery; Srednevolzhskaya culture; Samarskaya culture; Khvalynskaya culture; Lebyazhinskiy type; Tokskiy type; Gundorovskiy type; ceramics «with an internal edge»; Chekalinskiy type; Turganikskiy type.

УДК 902.6

DOI 10.24411/2309-4370-2019-12220

Статья поступила в редакцию 26.01.2019

\section{К ВОПРОСУ О «ПЕРЕЖИТОЧНОМ НЕОЛИТЕ» ЛЕСОСТЕПНОГО ДОНА}

(C) 2019

Ставицкий Владимир Вячеславович, доктор исторических наук, профессор кафедры всеобщей истории и обществознания

Пензенский государственный университет (2. Пенза, Российская Федераџия)

Аннотация. Концепция «пережиточного неолита» была представлена А.Т. Синюком в его диссертации и в дальнейшем не претерпела существенных изменений. В её основу были положены статистикостратиграфические наблюдения по поселению Университетская 3. Здесь было выделено три неолитических этапа и четвертый этап «пережиточного неолита». Его начало было связано с появлением на Среднем Дону населения нижнедонской энеолитической культуры, которое вступило в контакт с племенами рыбноозерской культуры. Выводы были основаны на предположении, что хозяйство рыбноозерской культуры было присваивающим, а нижнедонской - производящим. Возможность их сосуществования объяснялась богатейшими экологическими ресурсами донской лесостепи, а также ориентацией на добычу разных пищевых ресурсов. Новые материалы не подтвердили энеолитический характер нижнедонской культуры. Топография расположения поселений свидетельствует о том, что как местные, так и пришлые племена занимали одну и ту же экологическую нишу. Начало энеолита на Среднем Дону следует связывать со среднестоговской культурой, население которой вытеснило или ассимилировало аборигенов. Периода сосуществования энеолитических и неолитических (пережиточных) культур не было ни на Среднем Дону, ни в лесостепном Поволжье.

Ключевые слова: пережиточный неолит; археологическая эпоха; стратиграфия; энеолит; среднедонская культура; нижнедонская культура; среднестоговская культура; лесостепь; Средний Дон; ямочно-гребенчатая керамика; производящее хозяйство; межэтнические контакты; погребальный обряд; рыбноозерская культура; экологическая ниша.

Концепция «пережиточного неолита» лесостепного Подонья была впервые представлена А.Т. Синюком в его кандидатской диссертации [1] и в дальнейшем не претерпела существенных изменений [2]. В её основу были положены статистико-стратиграфические наблюдения, полученные по результатам раскопок стоянки Университетская 3, где было выделено три неолитических этапа и четвертый этап «пережиточного неолита». На двух первых этапах происходило развитие местных неолитических традиций среднедонской неолитической культуры (нижний слой стоянки), которые на третьем этапе были осложнены проникновением носителей керамики долговского типа (нижняя часть среднего слоя). Начало «пережиточного неолита» было связано с появлением в нижней части среднего слоя воротничковой керамики нижнедонской энеолитической культуры, носители которой вступили в контакты с племенами рыбноозерской культуры ямочно-гребенчатой керамики, мигрировавшими с территории Верхнего Подонья [1, с. 8-16].

Вывод о неолитическом характере рыбноозерской культуры базировался на предположение о сохранении её носителями присваивающего хозяйства, основанного на охоте, при постепенно возрастающей роли рыбной ловли. Энеолитическая принадлежность нижнедонской культуры была аргументирована наличием близких аналогий в материалах Мариупольского и Никольского могильников. Кроме того, было выдвинуто предположение, что основным занятием нижнедонского населения являлось скотоводство и в определенной степени земледелие [1, с. 20].

Впоследствии данная концепция была дополнена положением о том, что богатейшие экологические ресурсы лесостепи способствовали установлению относительно мирных отношений, и это обусловило длительный период сосуществование в регионе населения с различными хозяйственными укладами: пережиточнонеолитическим (присваивающим) и энеолитическим (производящим) [3, с. 69]. При этом под термином «пережиточный неолит» А.Т. Синюк подразумевал именно длительное сосуществование культур с разными хозяйственными укладами в пределах одной и той же территории, что, по его мнению, было возможно только в крайне благоприятных условиях лесостепи, богатой природными ресурсами. Кроме того, им было внесено уточнение о том, что под лесостепным энеолитом следует понимать эпоху, связанную с распространением не только металлов, но и сопутствующих им взаимообусловленных признаков, характеризующих археологическую специфику металлоносного района, откуда были привнесены медные изделия. Если же металлические изделия попадают в новый район, а в местных культурах не фиксируется изменения бытовых устоев, то такие культуры не следует относить к энеолитическим [4, с. 8-9].

В совместной работе А.Т. Синюка и И.Б. Васильева были конкретизированы те изменения в эконо- 